\title{
Neuer technischer Geschäftsführer bei ViscoTec
}

B ereits seit dem 1. Januar 2013 ist Martin Stadler neuer technischer Geschäftsführer bei ViscoTec in Töging. Er folgt auf Vinzenz Gantenhammer, der seit der Gründung des Unternehmens im Jahre 1997 diese Position innehatte und jetzt in den wohlverdienten Ruhestand verabschiedet wurde. Neben Georg Senftl, der weiterhin den kaufmännischen Bereich verantwortet, möchte Martin Stadler nun für alle Geschäftsfelder dafür sorgen, dass deren Produkte auch zukünftig die Maßstäbe für präzises, schnelles volumetrisches Dosieren setzen. Der 45-jährige Maschinenbau-Ingenieur bringt als bisheriger Leiter des Geschäftsfeldes Kleben und Chemie eine mehr als 10-jährige Erfahrung in der Konstruktion, Entwicklung und im Vertrieb von Dosieranlagen und Dosierkomponenten mit.

Die ViscoTec Pumpen- $u$. Dosiertechnik GmbH umfasst weltweit knapp 100 Mitarbeiter und fertigt in Töging Dosieranlagen sowie Komponenten, die z. B. zum Auftragen von Klebstoffraupen in vollautomatischen Montageprozessen verwendet werden.

\section{Messe über Kunststoffverarbeitung in Polen}

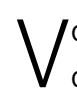

om 7. bis zum 10. Mai 2013 werden ca. 700 Aussteller aus mehr als 30 Ländern im polnischen Kielce auf der Plastpol, 17. Internationale Messe für Kunststoff- und Gummiverarbeitung, ihre Produkte präsentieren. Der Veranstalter erwartet mehr als 17.000 Besucher, die sich hinsichtlich neuer Entwicklungen und Trends in der Kunststofftechnik auf den aktuellen Stand bringen möchten. Im Mittelpunkt der diesjährigen Veranstaltung stehen neueste Techniken auf dem
Gebiet der Kunststoff- und Gummibearbeitung und die zunehmende Einbindung modernster IT-Systeme in alle möglichen Formen der Kunststoffbearbeitung.

Die Messe wird bereits zum siebzehnten Mal durchgeführt und gilt nicht nur als größte internationale Fachmesse der Branche in Polen, sondern mittlerweile auch als Leitmesse der Kunststoffverarbeitung für Mittelosteuropa.

Weitere Infos: www.targikielce.pl
Zur diesjährigen Plastpol erwartet der Veranstalter mehr als 17.000 Besucher.

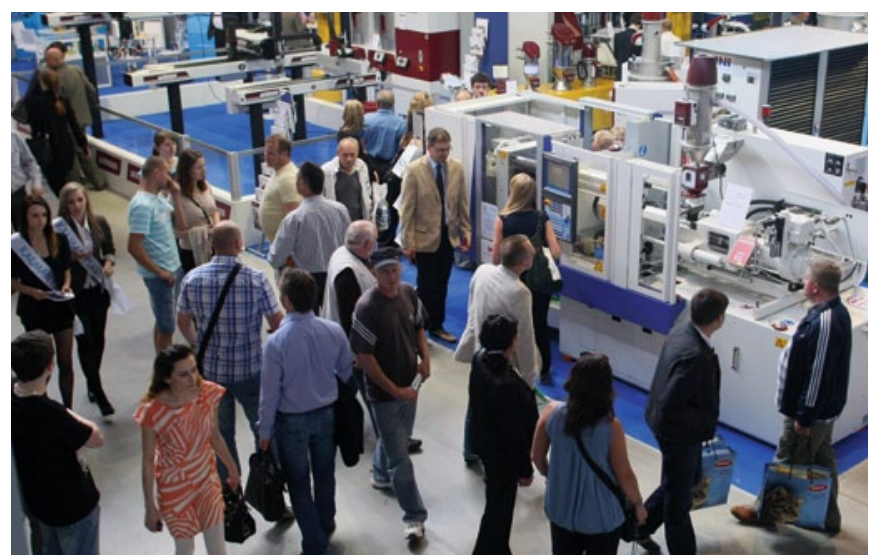

\section{Erweiterte Geschäftsführung}

D as Unternehmen Ardex, Anbieter bauchemischer Produkte, ergänzt zum 01.04.2013 sein Führungsgremium um Dr. Ulrich Dahlhoff, der als Geschäftsführer für Vertrieb und Marketing für die Regionen Deutschland, Benelux und die Schweiz zuständig sein wird. Außerdem übernimmt er die Verantwortung für die Anwendungstechnik, die erheblich ausgebaut und eine Einheit mit den Aktivitäten im Vertriebs- und Marketingbereich bilden soll.

In der Geschäftsführung des Stammhauses in Witten wird Dr. Dahlhoff neben dem Vorsitzenden Mark Eslamlooy, der in Personalunion auch die Ardex Gruppe leitet, und Dr. Rüdiger Oberste-Padtberg, der u. a. für Forschung \& Entwicklung, Einkauf und Produktion zuständig ist, tätig sein. In seiner neuen Funktion tritt Dr. Dahlhoff auch die Nachfolge des Ende letzten Jahres unerwartet verstorbenen Vertriebsleiters Werner Schröder an.

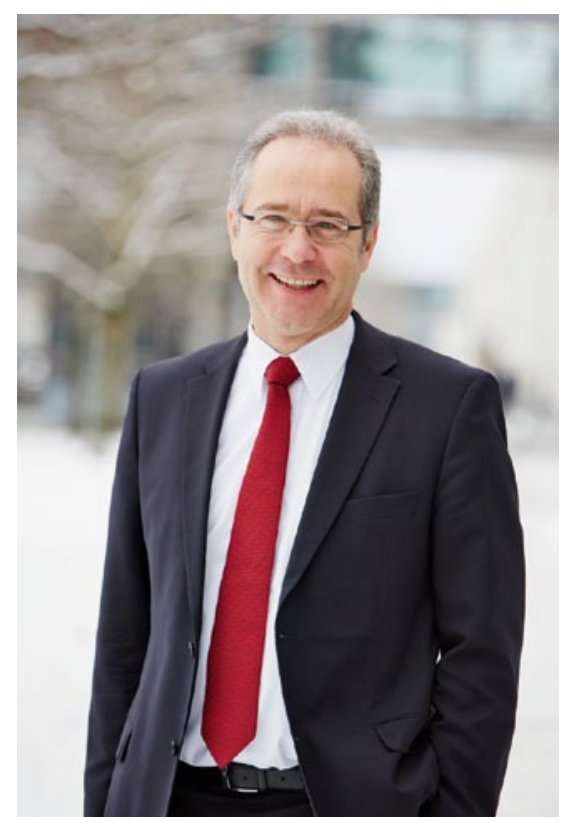

Dr. Ulrich Dahlhoff ergänzt die Geschäftsführung des BauchemieAnbieters Ardex 